\title{
Jogo Digital como Auxílio no Estudo da Matemática: Um Estudo de Caso com Estudantes do Ensino Fundamental I
}

\author{
Pedro Henrique Macêdo1, Mirele Moutinho Lima², Wylliams Santos ${ }^{12}$ \\ ${ }^{1}$ Sistemas de Informação - Universidade de Pernambuco (UPE) \\ 55014-908 - Caruaru - PE - Brazil \\ ${ }^{2}$ Centro de Informática - Universidade Federal de Pernambuco (UFPE) \\ Recife - PE - Brazil \\ pedroh.programacao@gmail.com ,\{mirele.moutinho, wbs\}@upe.com
}

\begin{abstract}
Studies present a concern regarding the process of teaching and learning Maths in Elementary School. This work aims to develop and apply an educational game as a complement to the activities studied in the classroom by primary school students to verify the use of digital content in classroom. A case study was conducted to verify the use of technology in school settings. As results of this study, it was possible to realize a great acceptance of the Pizzaria Dividendo game by the students and increase in the school performance. The game is a complementary tool to the teaching-learning process, since it influences the student's motivation and performance.
\end{abstract}

Resumo. Estudos apresentam uma preocupação em relação ao processo de ensino e aprendizagem da Matemática no Ensino Fundamental. Este trabalho visa desenvolver e aplicar um jogo educacional como complemento das atividades estudadas em sala de aula por alunos do Ensino Fundamental para analisar o uso do conteúdo digital em sala de aula. Foi conduzido um estudo de caso para verificar a utilização da tecnologia no âmbito escolar. Como resultados deste estudo, foi possivel perceber uma grande aceitação do jogo Pizzaria Dividendo por parte dos alunos e aumento no desempenho escolar. $O$ jogo é uma ferramenta complementar ao processo de ensino-aprendizagem, dado que influencia na motivação e desempenho do aluno.

\section{Introdução}

Com o avanço da tecnologia, é possível verificar a utilização da mesma em hábitos do nosso cotidiano. Segundo dados do IBGE (2015) 75\% da população brasileira tem acesso a pelo menos um aparelho celular para uso pessoal. Essa mesma pesquisa também informa que $75,2 \%$ das crianças ou adolescentes com 10 ou mais anos de idade que frequentam escolas possuem aparelhos telefônicos. O que significa que a tecnologia também faz parte do cotidiano dos estudantes do Ensino Fundamental e Ensino Médio.

O uso da tecnologia como computadores e telefones não está restrito a reuniões de trabalho ou escritórios como há alguns anos atrás. Com a presença da tecnologia para uso pessoal, surgiram os mais diversos tipos de aplicativos. Exemplifica-se com uma quantidade de 1,43 milhões de aplicativos na loja do Google para aparelhos Android, a Play Store, como afirma o portal Appfigures (2015). 
O uso desses aplicativos variam de entretenimento a educação. Porém, mesmo com bons aplicativos que podem ser utilizados para educação, esta tecnologia ainda não encontra forças para estar presente nas escolas do país. Isso se deve ao fato de que muitos dos professores não conseguem conciliar o uso da tecnologia com a educação (Nobre, 2014).

Martins (2016) afirma que as escolas ainda têm a necessidade de desenvolver, ou utilizar, novas metodologias que consigam conciliar o conhecimento em seus diversos níveis com a capacidade das crianças e dos adolescentes de aprenderem em diversos contextos. Sendo assim é necessário que as escolas possam atualizar suas metodologias, para que estas consigam reter seus alunos, utilizando-se de meios comuns no cotidiano de seus jovens estudantes, guiando-os no uso das tecnologias para fins de estudos. A adoção de jogos educativos e demais recursos disponíveis é uma forma de fomentar o interesse dos estudantes, como concluiu Pires (2015).

Componentes curriculares como Matemática, Física e Química tendem a ser encaradas como as áreas mais difíceis para assimilar. Em relação à matemática, $50 \%$ dos estudantes tendem a ter algum tipo de rejeição à matéria segundo o portal Todos Pela Educação (TPE) (2015). Esses dados ficam ainda mais alarmantes quando visto que $65 \%$ dos adultos têm dificuldades com matemática básica, e estes assumem que essa dificuldade surgiu desde os primeiros anos escolares (TPE, 2015). A dificuldade apresentada no aprendizado da Matemática está geralmente em seus aspectos teóricos, pois é vista como uma matéria abstrata, sendo difícil de associar com a realidade.

Com base nas dificuldades apresentadas, este trabalho propõe a utilização de jogos educativos em sala de aula como uma ferramenta auxiliar no processo de ensinoaprendizagem, focando em estudantes do $5^{\circ}$ ano do Ensino Fundamental. Este artigo apresenta na Seção 2 os benefícios da utilização da tecnologia e dos jogos educacionais em sala de aula, verificando também as principais dificuldades deste tipo de aplicação. Aborda os trabalhos relacionados na Seção 3, o estudo de caso é apresentado na Seção 4, logo após, na Seção 5, apresenta o jogo proposto neste trabalho. Por fim os resultados são apresentados na Seção 6 e as conclusões na Seção 7.

\section{Jogos Educativos em Sala de Aula}

Com as mudanças ocorridas na sociedade, surgiu uma necessidade de mudar a metodologia utilizada na educação, removendo a ideia de que o aluno é apenas um agente passivo que recebe todo o conteúdo e adicionando o modelo onde toda a aprendizagem é dinâmica, onde o aluno poderá interagir com o que está aprendendo. Segundo Kenski (2007, apud Leite 2014) a tecnologia da informação possibilita essa interação dos professores com os estudantes. Mostra-se então que o conceito da Informática na Educação torna-se algo promissor e necessário.

Porém o conceito da Informática na Educação não é algo novo, segundo Valente (1991) o conceito surgiu na década de 1960, com a instrução auxiliada por computador, ou "computer-aided instruction", também conhecida como CAI. Porém devido aos altos preços dos computadores na época, os aparelhos demoraram décadas para finalmente chegarem às escolas, o que só ocorreu com a chegada dos microcomputadores no mercado. 
Com a necessidade de levar a tecnologia para a sala de aula, era necessário estudar como utilizar de forma eficaz esta nova metodologia, pois, como é mencionado por Leite (2014), apenas a tecnologia da informação não gera melhorias, é preciso planejar como utilizá-la no ambiente escolar. Sendo assim, é perceptível que a tecnologia aplicada em sala de aula apresenta um melhor desempenho quando está ligada aos conceitos presentes no cotidiano do estudante. Uma forma viável e eficaz de levar essa novidade ao estudante, é com jogos digitais (Silva Neto, 2013).

Os jogos eletrônicos conseguem fazer com que seus jogadores fiquem longos períodos de tempo totalmente concentrados em seus desafios, e assim, muitas vezes não percebendo distrações externas, afirma Savi (2008). E esta capacidade de retenção que os jogos eletrônicos apresentam ao jogador fez com que surgissem pesquisas de como utilizar esta tecnologia para a educação.

Apesar de haver rejeição por parte de alguns professores (Silva Neto, 2013), os jogos eletrônicos podem ser utilizados na educação, porém precisam de algumas características específicas para serem considerados jogos educacionais, afirma Savi (2008). Segundo Prieto (2005), estes “devem possuir objetivos pedagógicos e sua utilização deve estar inserida em um contexto e em uma situação de ensino baseado em uma metodologia que oriente o processo, através da interação, da motivação e da descoberta, facilitando a aprendizagem de um conteúdo".

E além da motivação já citada, os jogos oferecem diversos benefícios aos seus jogadores, de acordo com Savi (2008). Pode-se destacar o fato de jogos serem facilitadores da aprendizagem, já que os jogadores passarão por mundos simulados com uma grande variedade de conteúdo e com desafios complexos e diferentes. Podendo assim levar ao estudante conteúdos que muitas vezes são difíceis de serem assimilados spor este. Outro destaque também ao fato de que o jogador aprende a partir da descoberta, ele poderá errar e tentar novamente enquanto joga, explorando as diversas possibilidades para se chegar a uma solução viável.

Além disso, os jogos podem ensinar valores filosóficos e sociais para o estudante, como a cooperação e a competitividade presente entre os jogadores durante as partidas, estes conceitos ajudam o jogador a interagir com as pessoas ao seu redor. Mesmo com os vários benefícios apresentados, ainda é difícil de encontrar os jogos eletrônicos em âmbito escolar. Essa dificuldade de levar o jogo à sala de aula é causada por diversos fatores, mas principalmente pela falta de integralização entre os projetos pedagógicos e os bons jogos com propósitos educacionais, fazendo assim com que os professores ainda não estejam capacitados para o uso desta tecnologia em sala de aula (Nobre, 2015).

Calisto (2010) apresenta outro problema relacionado aos jogos educacionais que é a grande dificuldade em encontrar jogos educacionais excelentes em relação ao equilíbrio entre o conteúdo abordado no jogo e a parte lúdica. Isso acontece porque os jogos educacionais tendem a focar mais para uma dessas áreas, fazendo com que o conteúdo final seja ou muito pedagógico, mas pouco atrativo para o estudante, ou divertido, porém com poucos detalhes pedagógicos, como é apresentado por Savi (2009). 
VI Congresso Brasileiro de Informática na Educação (CBIE 2017)

Anais do XXIII Workshop de Informática na Escola (WIE 2017)

\section{Trabalhos Relacionados}

Neto (2013) propôs a utilização de jogos educativos para o ensino de matemática de estudantes do $9^{\circ}$ ano do Ensino Fundamental e $1^{\circ}$ ano do Ensino Médio. Este criou um jogo para a plataforma Android. Apesar dos resultados positivos, este apresentou também a dificuldade de aplicar jogos educativos em sala de aula.

Santos (2016) estuda como virtualizar jogos já utilizados em sala de aula para ensinar matemática, tentando manter o conteúdo pedagógico dos jogos, porém levando novas mecânicas que se adaptem aos jogos eletrônicos. Os jogos digitalizados durante o estudo foram eficazes como mecanismo de apoio ao ensino-aprendizagem de determinados conteúdos matemáticos.

No trabalho apresentado por Pereira (2016) foi realizada uma pesquisa-ação com o intuito de aplicar jogos educativos no ambiente escolar. Este foi aplicado com estudantes do $8^{\circ}$ e $9^{\circ}$ ano do Ensino Fundamental em uma escola onde os estudantes apresentavam grandes dificuldades nos assuntos relacionados à matemática. Estes sentiram-se interessados e participavam ativamente do projeto proposto. Houve melhoria significativa em relação ao desempenho dos estudantes.

Já Leite (2014) sugeriu o ensino de Química a estudantes do Ensino Médio com a ajuda de aparelhos móveis, utilizando-se de pesquisas on-line, vídeos, imagens e áudios que explicassem os assuntos propostos aos participantes. Apesar de muitos dos estudantes afirmarem nunca terem utilizado seus aparelhos celulares para estudar, este trabalho mostrou que a utilização do celular teve um grande índice de aceitação por parte dos estudantes, além de atingir os resultados desejados em relação ao aprendizado dos participantes.

Silva Neto (2013) utilizou os jogos educacionais com estudantes do Ensino Médio como ferramenta para auxiliar os estudos de matérias com altos índices de rejeição. Este, durante a execução de seu projeto, percebeu o abandono dos laboratórios de informática que raramente eram utilizados e que esta realidade mudou após a aplicação de seu trabalho.

Por sua vez, Pires (2015) e Sales (2010) propuseram jogos para auxiliar estudantes do Ensino Superior. Pires (2015) propôs um jogo voltado ao ensino de Banco de Dados, visto a dificuldade de encontrar jogos relacionados a esta área de ensino. Enquanto Sales (2010), ao verificar o grande índice de reprovação nas componentes curriculares de lógica e algoritmo, propôs um jogo para que estudantes pudessem aprimorar-se nestas áreas. Os dois trabalhos tiveram resultados positivos. Oliveira (2014) com o objetivo de ensinar lógica de programação para os jovens do Ensino Fundamental, utilizou-se da criação de jogos com a ferramenta Scratch. Com os resultados apresentados pode-se verificar a importância de levar a informática aos estudantes do Ensino Fundamental.

Este trabalho difere-se dos demais ao utilizar os jogos educativos para estudantes mais novos, sendo eles do $5^{\circ}$ ano do Ensino Fundamental, visando utilizar a tecnologia e os jogos educativos como uma forma alternativa de auxílio pedagógico. 


\section{Estudo de Caso}

Nos últimos anos, muitos pesquisadores [Creswell 2013] [Seaman 1999] identificaram que a na seleção do método de pesquisa adequado no contexto de computação pode ser uma atividade desafiadora. Neste sentido, o presente trabalho adotou o guia (Figura 1) para desenvolvimento de estudo de caso proposto em [Runeson 2012]. O primeiro passo do estudo de caso define o design e planejamento do estudo. O segundo passo, preparação para a coleta de dados, define o protocolo e procedimentos do estudo. $\mathrm{O}$ terceiro passo coleta de evidências e o quarto foca nos procedimentos de análise dos dados. Finalmente, o último passo tem o objetivo de reportar a análise do estudo.

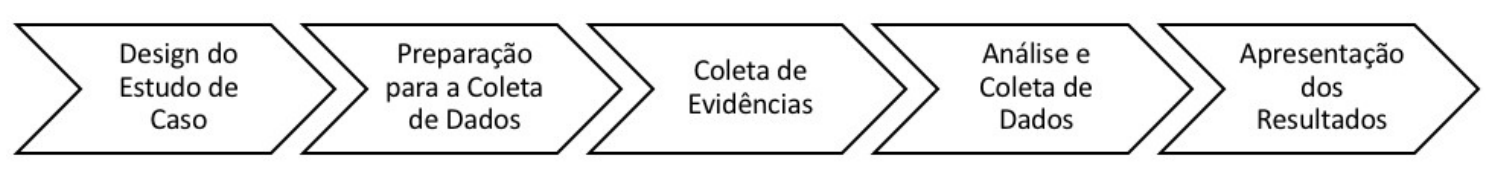

Figura 1. Processo para condução do estudo de caso [Runeson 2012]

\subsection{Contexto}

Este trabalho tem como objetivo analisar a utilização de jogos educativos como ferramenta auxiliar em sala de aula. Deseja-se verificar se os jogos educativos funcionam como ferramenta auxiliar no desempenho escolar dos estudantes, principalmente em componentes curriculares com grandes índices de rejeição, como a Matemática.

A partir deste objetivo é possível formular 3 perguntas:

- Os jogos eletrônicos costumam ser utilizados em sala de aula?

- Existem dificuldades em aplicar jogos educativos no âmbito escolar?

- Os Jogos e Softwares educativos ajudam no desempenho escolar dos estudantes?

\subsection{Seleção do Caso e Participantes}

Para responder as perguntas apresentadas um jogo foi projetado, elaborado e aplicado aos estudantes de uma escola que ainda não utiliza esta tecnologia em sua metodologia atual. Sendo assim, foi decidido o colégio que participaria do estudo e também foram escolhidos os estudantes do $5^{\circ}$ ano do Ensino Fundamental.

Sobre o colégio escolhido, este é uma instituição privada, que teve seu laboratório de informática desmontado por falta de uso. Apesar de fornecerem equipamentos, estes não eram utilizados pelos professores.

A turma era composta de 26 estudantes ao todo; estes faziam parte da mesma turma escolar, com uma faixa etária de 10 anos de idade. Todos os alunos puderam participar do experimento que aconteceu durante o horário de aula e dentro da sala de aula. Os estudantes receberam o jogo Pizzaria Dividendo em aparelhos fornecidos pelo colégio e também em seus aparelhos celulares, já que a escola não apresentava material suficiente para todos os alunos, tendo apenas 12 Tablets disponíveis. 


\subsection{Procedimento de Coleta de Dados}

Para que fosse possível medir o desempenho dos estudantes antes e após a utilização do jogo educativo criado, foram elaborados dois exercícios, cada um com 5 questões, com a aprovação da professora de matemática da turma. Sendo assim foram avaliados os conhecimentos do estudante em relação ao assunto matemático escolhido para o trabalho. Após a aplicação dos exercícios, as notas destes foram comparadas para verificar se houve realmente alguma mudança em suas notas.

Durante a aplicação do jogo, os estudantes puderam tirar dúvidas sobre o assunto tema apresentado no aplicativo. Na primeira aplicação do jogo em sala de aula, os alunos presentes receberam uma pequena apresentação de como jogar, para que estes pudessem se familiarizar com o jogo, facilitando então a absorção do conteúdo por parte das crianças.

Durante a realização do projeto, foi elaborado e entregue um questionário aos professores da escola. Este questionário abordava o uso da tecnologia em sala de aula. Como resultado, $66,7 \%$ dos professores questionados dizem sentir algum tipo de dificuldade ao utilizar a tecnologia em sala de aula. Das principais dificuldades apresentadas destacavam-se a falta de conhecimento de bons softwares educativos e a má utilização por parte dos alunos, já que estes utilizavam os aparelhos para outros fins como redes sociais.

\section{Pizzaria Dividendo}

Baseando-se no público alvo desta pesquisa, os estudantes do $5^{\circ}$ ano do Ensino Fundamental, o jogo Pizzaria Dividendo buscou unir o assunto matemático, números fracionários, com um tema que atraísse o interesse da criança. Partindo do fato que crianças gostam de pizzas, toda a ambientação do jogo é baseada em uma pizzaria, onde o jogador deverá atender os clientes que aparecerão com diferentes pedidos, para montar sua refeição, que é composta de pizza e sucos. Estes pedidos aparecerão em forma de frações como é apresentado na Figura 2.

Todos os pedidos dos clientes são gerados de maneira aleatória, impedindo que o jogador possa decorar as respostas para passar de nível. O estudante tem um tempo para resolver o problema, caso o cliente não seja atendido nesse período, este irá embora e o jogador receberá a notificação de que um erro foi cometido. O jogador poderá errar apenas 2 vezes por estágio, pois ao errar a terceira vez aparecerá a tela de fim de jogo e caso queira continuar jogando, será necessário recomeçar o a fase. 
VI Congresso Brasileiro de Informática na Educação (CBIE 2017)

Anais do XXIII Workshop de Informática na Escola (WIE 2017)

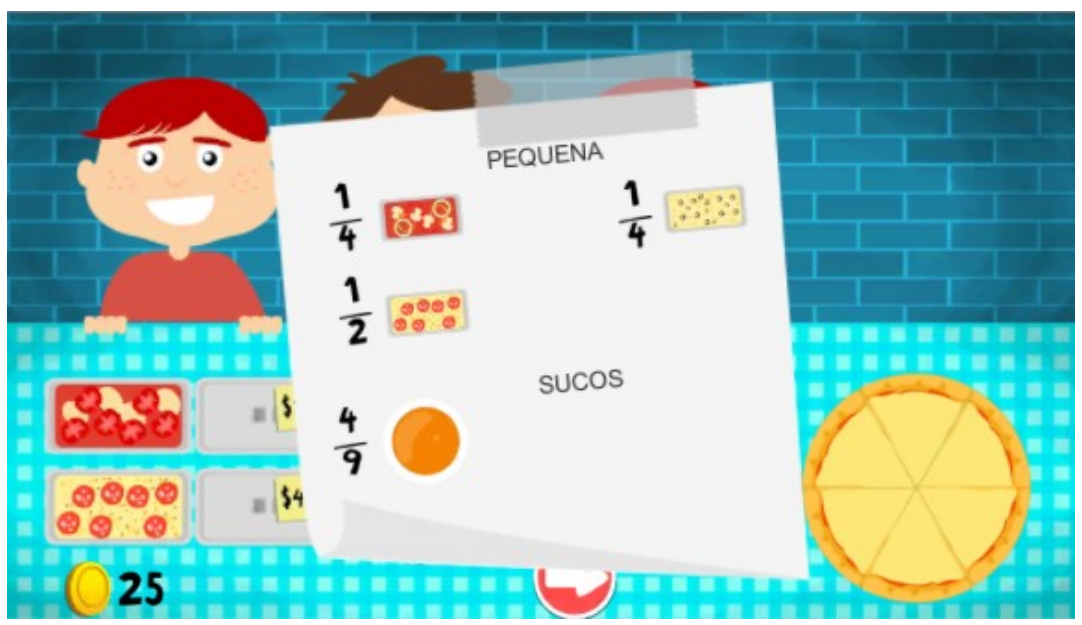

Figura 2. Imagem do pedido do cliente no jogo.

Como já citado, o pedido é composto pela pizza e pelas bebidas. O jogador deverá completar estes pedidos seguindo a ordem de que a pizza deve ser montada primeiro, e só após concluir a montagem da pizza, deve-se partir para a bandeja de sucos. Para montar a pizza o estudante recebe duas informações importantes, o tamanho da pizza e a quantidade de fatias de cada um dos sabores. Já na parte dos sucos apenas é informado quantos copos de suco de cada sabor o cliente deseja. É importante notar que a soma das fatias da pizza equivale a um inteiro, porém a quantidade de copos em uma bandeja de suco geralmente não representa a capacidade máxima de 9 copos, estas informações podem ser vistas na Figura 2.

As pizzas têm quantidades de fatias diferentes de acordo com o tamanho. Pizzas pequenas apresentam apenas 4 fatias, as médias apresentam 6 fatias e as grandes, 8, como pode ser visto na Figura 3. Essa diversidade permite ao jogo apresentar um maior número de frações em seus problemas. Já a bandeja de sucos sempre terá capacidade para 9 copos, mesmo que o pedido não chegue a atingir a capacidade máxima de copos.

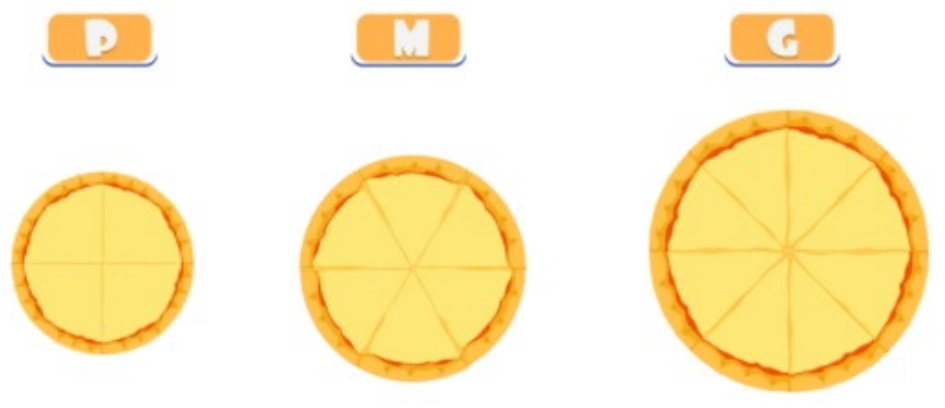

Figura 3. Pizzas e seus tamanhos.

Além da temática atrativa, outros fatores como a arte colorida, a música ambiente e a fácil jogabilidade foram pontos chaves para fazer com que o jogo tivesse uma boa aceitação por parte dos estudantes. O Pizzaria Dividendo apresenta um total de 20 estágios mais uma fase tutorial. Essas fases seguem uma progressão de dificuldade, 
VI Congresso Brasileiro de Informática na Educação (CBIE 2017)

Anais do XXIII Workshop de Informática na Escola (WIE 2017)

fazendo com que o jogador possa sentir-se desafiado e estimulado a resolver os problemas da melhor forma possível.

Os estágios presentes são criados seguindo uma sequência de variáveis previamente informadas em seu código fonte. Ao iniciar o estágio, essas informações são checadas e enquanto um novo estágio não for iniciado, o jogo seguirá as regras definidas por essas variáveis para gerar seus clientes. A Tabela 1 apresenta os valores atribuídos a cada uma das variáveis em cada estágio. As variáveis são: Dificuldade, Número de Clientes que deverão ser atendidos, Tempo de Espera que o cliente poderá ficar antes de ir embora, Tempo de Criação de um Novo Cliente que define quantos segundos o jogo esperará até que crie um novo pedido e Sabores Desbloqueados que representa quais sabores presentes no jogo poderão fazer parte do pedido dos clientes.

O software Pizzaria Dividendo pode ser instalado em aparelhos Android e está disponível no link: https://goo.gl/HL5Nfx

Tabela 1. Valores atribuídos aos estágios.

\begin{tabular}{|c|c|c|c|c|c|}
\hline Estágio & Dificuldade & $\begin{array}{l}\text { Número de } \\
\text { Clientes }\end{array}$ & $\begin{array}{c}\text { Tempo de } \\
\text { Espera } \\
\text { (Em Segundos) }\end{array}$ & $\begin{array}{c}\text { Tempo de } \\
\text { Criação do Cliente } \\
\text { (Em Segundos) }\end{array}$ & $\begin{array}{c}\text { Sabores } \\
\text { Desbloqueados }\end{array}$ \\
\hline 1 & Fácil & 6 & 200 & 40 & 2 \\
\hline 2 & Fácil & 10 & 240 & 30 & 3 \\
\hline 3 & Fácil & 11 & 180 & 30 & 3 \\
\hline 4 & Fácil & 7 & 150 & 35 & 4 \\
\hline 5 & Fácil & 14 & 180 & 20 & 4 \\
\hline 6 & Médio & 9 & 200 & 30 & 4 \\
\hline 7 & Médio & 12 & 180 & 30 & 5 \\
\hline 8 & Médio & 10 & 180 & 22 & 5 \\
\hline 9 & Médio & 13 & 200 & 15 & 5 \\
\hline 10 & Médio & 15 & 180 & 25 & 5 \\
\hline 11 & Médio & 10 & 150 & 30 & 6 \\
\hline 12 & Médio & 8 & 200 & 15 & 6 \\
\hline 13 & Difícil & 8 & 240 & 30 & 6 \\
\hline 14 & Difícil & 10 & 200 & 25 & 6 \\
\hline 15 & Difícil & 7 & 230 & 15 & 6 \\
\hline 16 & Difícil & 10 & 175 & 25 & 6 \\
\hline 17 & Difícil & 10 & 150 & 30 & 6 \\
\hline 18 & Difícil & 10 & 180 & 20 & 6 \\
\hline 19 & Difícil & 6 & 100 & 15 & 6 \\
\hline 20 & Difícil & 30 & 150 & 15 & 6 \\
\hline
\end{tabular}




\section{Resultados e Discussões}

Como resultados deste estudo de caso, foi possível notar uma grande aceitação do jogo Pizzaria Dividendo por parte não só dos estudantes participantes, mas também dos professores do colégio que se sentiram atraídos pela utilização da tecnologia em sala.

No início os estudantes que participaram do estudo de caso não apresentaram dificuldades ao jogar, resolvendo os problemas com certa facilidade. À medida que passavam de estágio e o jogo tornava-se mais desafiador, as crianças passaram a se concentrar mais para poder resolver os problemas apresentados e continuar progredindo no jogo.

Para medir se houve um aumento no desempenho dos estudantes, foram aplicados dois testes, sendo um deles antes do experimento com o jogo e outro após o experimento. Neste teste, havia questões de matemática com o tema que seria abordado pelo jogo. Apesar de não ter tido uma mudança significativa no resultado dos testes aplicados, foi possível notar que houve melhora no desempenho das crianças enquanto jogavam, já que ao final do experimento os estudantes conseguiam resolver com facilidade problemas que estes tinham dificuldades anteriormente, no começo do experimento.

\section{Conclusão e Próximos Passos}

A partir dos resultados apresentados por esta pesquisa, é possível concluir que o jogo educativo pode ser uma ótima ferramenta para o auxílio do professor, porém a utilização do mesmo deve ser bem planejado para que possam surtir efeitos positivos no desempenho dos estudantes.

É visível que a tecnologia ainda é novidade em sala de aula, e a utilização da mesma deve ser uma prática planejada não só por professores, mas por toda a gestão da escola, pois apenas o software para a sala de aula não é suficiente, deve ser considerado todo o equipamento e suporte necessário para a utilização dos mesmos.

A utilização de jogos em sala de aula contribui como fator motivacional, ajudando a reter a atenção da criança, porém ainda é necessário que os estudantes sejam orientados na forma de utilizar as tecnologias como ferramenta de auxílio aos estudos. $\mathrm{E}$ esta metodologia deve ser ensinada para os estudantes em seus primeiros anos escolares.

Por fim, é importante destacar que não há um padrão na criação de jogos educativos, mas para que estes possam ser otimizados deve-se balancear a parte lúdica do jogo e a educativa. Assim como é importante que novas pontes entre desenvolvedores e educadores surjam, já que ainda existe a falta de conhecimento de bons softwares disponíveis para o auxílio dos estudos. Como oportunidades para o desenvolvimento de trabalhos futuros, espera-se a condução de mais estudos empíricos em cenários similares de forma a mitigar as ameaças à validade do estudo.

\section{Referências}

AppFigure (2014), “App Stores Growth Accelerates in 2014”, http://blog.appfigures.com/app-stores-growth-accelerates-in-2014. Acesso em: 19 de set de 2016. 
VI Congresso Brasileiro de Informática na Educação (CBIE 2017)

Anais do XXIII Workshop de Informática na Escola (WIE 2017)

Calisto, A., Barbosa, D. and Silva, C. (2010). "Uma Análise Comparativa entre Jogos Educativos Visando a Criação de um Jogo para Educação Ambiental”. In Brazilian Symposium on Computers in Education (Simpósio Brasileiro de Informática na Educação-SBIE) (Vol. 1, No. 1).

Creswell, J. (2013). "Research Design: Qualitative, Quantitative and Mixed Methods Approach." SAGE Publications, Inc, 4th edition.

IBGE (2015). "Acesso à Internet e à Televisão e Posse de Telefone Móvel Celular para Uso Pessoal 2015", http://www.ibge.gov.br/home/estatistica/populacao/acessoainternet2015/default.shtm . Acesso em: 12 de jan de 2017.

Leite, B. S. (2014). "M-Learning: O Uso de Dispositivos Móveis como Ferramenta Didática no Ensino de Química”. Revista Brasileira de Informática na Educação, 22(3), 1.

Martins, E. and Lautert, S. (2016). "Diálogos sobre o Ensino, Aprendizagem e a Formação de Professores", Autografia, $1^{\text {a }}$ edição.

Neto, J. F. B. and da Fonseca, F. D. S. (2013). "Jogos Educativos em Dispositivos Móveis como Auxílio ao Ensino da Matemática”. Revista Novas Técnicas na Educação (RENOTE), (Vol .11, No. 1, p. 1).

Nobre, R. H., et al. (2015). "Uso dos Laboratórios de Informática em Escolas do Ensino Médio e Fundamental no Interior Nordestino". Revista Brasileira de Informática na Educação, 23(3).

Oliveira, M. L. S., de Souza, A. A., Barbosa, A. F. and Barreiros, E. F. S. (2014). "Ensino de Lógica de Programação no Ensino Fundamental Utilizando o Scratch: um Relato de Experiência”. In XXXIV Congresso da SBC-XXII Workshop de Ensino de Computação, Brasília.

Pereira, A. B., et al. (2016). "Jogos Digitais no Desenvolvimento de Conceitos Matemáticos sob Perspectiva BYOD e Abordagem m-Learning na Escola Pública". In Anais do Workshop de Informática na Escola (Vol. 22, No. 1, p. 71).

Pires, C. E., et al. (2015). "Um Jogo Didático para Detecção de Problemas de Qualidade de Dados em Bancos de Dados Relacionais". Revista Brasileira de Informática na Educação, 23(03), 98.

Santos, W. O. and da Silva Junior, C. G. (2016). "Virtualização de Jogos Educativos: Uma Experiência no Ensino de Matemática. Revista Brasileira de Informática na Educação", 24(2).

Savi, R. and Ulbricht, V. R. (2008). "Jogos Digitais Educacionais: Benefícios e Desafios". Revista Novas Tecnologias na Educação, 6(2), 10.

Seaman. C. (1999) "Qualitative Methods in Empirical Studies of Software Engineering”. IEEE Transactions on Software Engineering, 25(4):557-572.

Silva Neto, S. R., et al. (2013). "Jogos Educacionais como Ferramenta de Auxílio em Sala de Aula". In Anais do Workshop de Informática na Escola (Vol. 1, No. 1, p. $130)$.

TPE (2015), Todos Pela Educação. Adultos não sabem matemática básica, segundo pesquisa. Disponível em: <http://www.todospelaeducacao.org.br/educacao-namidia/indice/35786/adultos-nao-sabem-matematica-basica-segundo-pesquisa $\quad 1>$. Acesso em: 24 de ago de 2016.

Valente, J. A. (1991). "Liberando a Mente: Computadores na Educação Especial". Campinas: Unicamp. 